\title{
Applications of the Direct Space Vector Modulation Controlled Matrix Converter as the Unified Power Flow Controller
}

\author{
J.W. Zhang*, D. G. Dorrell ${ }^{\dagger}$ and L. Li* \\ *Faculty of Engineering and Information Technology, University of Technology Sydney, Australia \\ University of KwaZulu-Natal, Howard College Campus, Durban 4041, South Africa \\ Jianwei.Zhang-1@student.uts.edu.au,dorrelld@ukzn.ac.za andLi.Li@uts.edu.au
}

Keywords: Matrix Converter, Space Vector Modulation, Power Flow Controller, FACTS, d q Decoupling.

\begin{abstract}
This paper investigates the matrix converter when working as the unified power flow controller which can regulate the active reactive power flowing in a transmission line. A conventional unified power flow controller usually has a DC capacitor; this is removed in the proposed controller. This reduces the volume, improves the efficiency and lifetime, and eliminates the DC voltage control. The detailed direct space vector modulation method for the matrix converter is described. Based on this modulation scheme, a PID controller is designed in order to control the power flow. Coupling effects are suppressed by feedback of the coupling components to the controller. The proposed strategy can control the active and reactive power efficiently and effectively. Simulations based on MATLAB/Simulink help verify the feasibility and effectiveness of the scheme.
\end{abstract}

\section{Introduction}

In recent years, the demands on power systems have intensified. It has also become more difficult to build new transmission lines in many countries so that many lines are working at full capacity. However, some transmission systems have not been fully exploited due to the need to transmit reactive as well as active power. In modern power systems, there is a need for power flow to be controlled flexibly, which cannot be fulfilled by the traditional grid networks. Therefore, it is desirable to increase the transmission capabilities of existing transmission systems. Flexible alternating current transmission systems (FACTS) provide a way to realise the full potential of transmission without building new lines [1]. And power electronic converters offer potential solutions for flexible power flow control.

The unified power flow controller (UPFC) [2], which uses power electronic technology to control grid power flow, has been recognized as the most versatile technology for FACTS. The UPFC was designed to solve the problems facing the power delivery industry such as real time control, dynamic compensation, and multifunctional flexibility [3]. Unlike other FACTS devices, the UPFC does not explicitly regulate the transmission parameters such as the impedance, line voltage and the transmission angle individually; instead it controls the active and reactive power by varying the sending end voltage and phase angle by controlling the voltage accordingly [4].

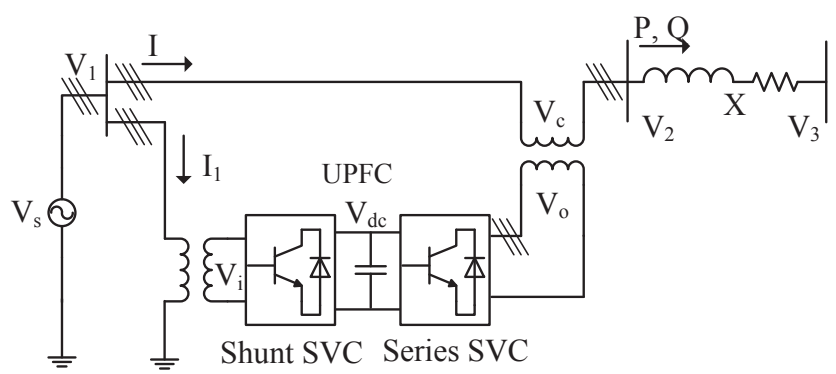

Fig. 1: Topology of the Traditional UPFC System

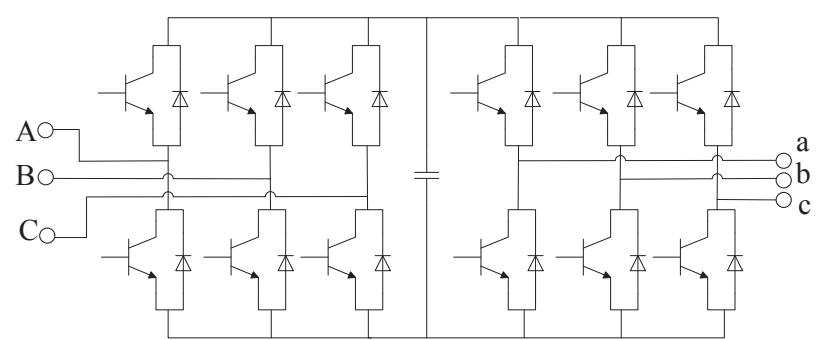

Fig. 2: Back to Back Converter Topology

The traditional UPFC (Fig. 1) employs back-to-back inverters (Fig. 2) which can carry out AC-to-AC conversion indirectly. A UPFC is a combination of a static synchronous compensator (STATCOM, shunt controller) and a static synchronous series compensator (SSSC, series controller) connected by a shared DC capacitor link. The STATCOM is connected in parallel in the grid and it can work as a controllable reactive-power current source, thus dynamically compensating for the reactive power. The SSSC is connected in series with the grid and produces voltages with controllable amplitude and phase angle for reactive power compensation, and thus it facilitates active power exchange in the transmission lines. As a result, the transmission capacity is increased. However, the capacitor in the traditional UPFC produces losses, increases the weight and volume, and deteriorates with time [5].

In contrast no DC capacitor needed in a matrix converter, as illustrated in Fig. 3. This has been extensively studied since it has advantages such as compact configuration, bidirectional power flow, high efficiency, controllable input power factor and longer life expectation [6]. The matrix converter carries 
out AC-to-AC conversion directly and it can be regarded as an alternative to conventional UPFCs.

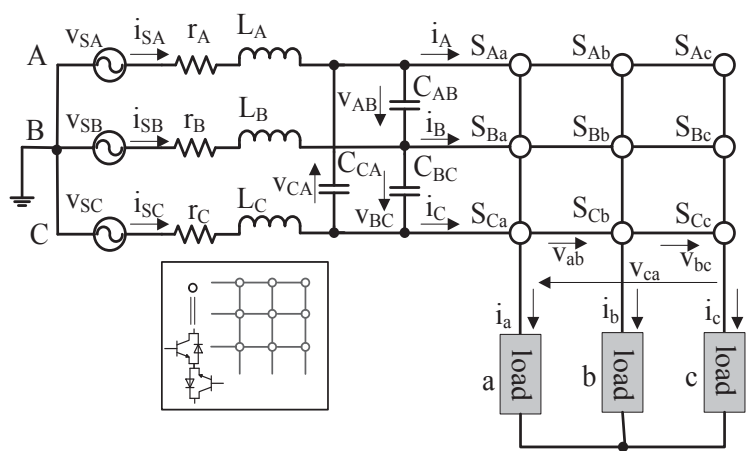

Fig. 3: Matrix Converter System with the Input Filters

For control of the matrix converter, direct space vector modulation (SVM) [7] is adopted here. This technique makes best use of the input voltage. It can reduce the number of commutation, control the input power factor independently, and provide better power quality. This technique is explained in Section 3. Various controllers have been used to control the UPFC [8]. In this paper, a PID controller is designed to control the power flow in a transmission line system. In order to reduce the $d-q$ coupling effects, the $d-q$ components are fed to the controller and the active and reactive power flow through the transmission line can be regulated. The system is simulated in order to support the proposition.

\section{UPFC System Description}

\subsection{Power Flows Control Theory}

A UPFC, when connected to transmission system, is shown in Fig. 4. Using the system configuration and notations in the figure, we can express the apparent power $\dot{S}$ through the transmission line as

$$
\dot{S}=P+j Q=\dot{V}_{L}\left(\frac{\dot{V}_{L}-\dot{V}_{r}}{Z}\right)^{*}
$$

where $j^{2}=-1, Z=R_{L}+j \omega L_{L}$ and $\omega=2 \pi f$ is the angular frequency. $R_{L}$ and $L_{L}$ are the transmission line resistance and inductance which form the impedance; the resistance can be ignored if the ratio of $\omega L_{\mathrm{L}}$ to $R_{\mathrm{L}}$ is very large, as it is in a high voltage transmission line [9]. Here $\dot{V}^{*}$ denotes the conjugate of $\dot{V}$, and phasors $\dot{V}_{\mathrm{L}}=\dot{V}_{\mathrm{s}}+\dot{V}_{\mathrm{c}}$ and $\dot{V}_{\mathrm{r}}$ are shown in Fig. 4.

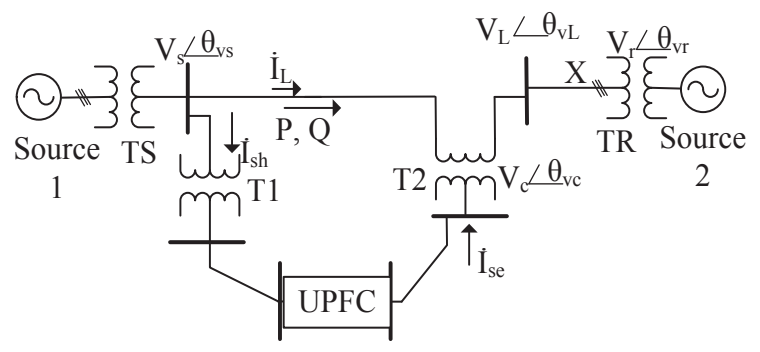

Fig. 4: Illustration of UPFC Power Flows Control

If the compensation voltage is zero, i.e., $\dot{V}_{\mathrm{c}}=0$, then $\dot{V}_{\mathrm{s}}=\dot{V}_{\mathrm{L}}$, and (1) can be rearranged to
$P_{0}+j Q_{0}=\dot{V}_{s}\left(\frac{\dot{V}_{s}-\dot{V}_{r}}{j \omega L}\right)^{*}=\frac{V_{s} V_{r} \sin \theta}{\omega L}+j \frac{V_{s}\left(V_{s}-V_{r} \cos \theta\right)}{\omega L}$

where $\theta=\theta_{\mathrm{vs}}-\theta_{\mathrm{vr}}$ is the transmission angle of the system. Analogously, when $\dot{V}_{\mathrm{c}} \neq 0$, the active and reactive powers through the line, depending on the calculation points, are formulated from

$$
\begin{aligned}
& P+j Q=\dot{V}_{s} \dot{I}_{L}^{*}=\dot{V}_{s}\left(\frac{\dot{V}_{s}+\dot{V}_{c}-\dot{V}_{r}}{j \omega L}\right)^{*} \\
& =\frac{1}{\omega L}\left\{\begin{array}{l}
{\left[\mathrm{V}_{s} \mathrm{~V}_{r} \sin \theta+j\left(\mathrm{~V}_{s}^{2}-\mathrm{V}_{s} \mathrm{~V}_{r} \cos \theta\right)\right]} \\
+\left[\mathrm{V}_{c} \mathrm{~V}_{s} \sin \left(\theta_{v c}-\theta_{v s}\right)+j \mathrm{~V}_{c} \mathrm{~V}_{s} \cos \left(\theta_{v c}-\theta_{v s}\right)\right]
\end{array}\right\} \\
& =\left(P_{0}+j Q_{0}\right)+\left(\Delta P_{1}+j \Delta \mathrm{Q}_{1}\right)
\end{aligned}
$$

The expression varies because the point voltages change while the current remains unchanged. According to (3) the active power and the reactive power through the lines are divided into the uncontrollable part (2) and the controllable part $\left(\Delta P_{1}\right.$ and $\left.\Delta Q_{1}\right)$. By controlling the amplitude and phase angle of the injected voltage $\dot{V}_{\mathrm{c}}$, the active and reactive powers through the transmission line can be regulated. In steady state, the UPFC, does not absorb or supply real power, except for its loss energy dissipation, unless there is a DC source in the DC link.

\subsection{Proposed UPFC with Matrix Converter}

A UPFC which utilizes a direct SVM controlled matrix converter is proposed and shown in Fig. 5. The transformers connect the input and output terminals of the UPFC. The input in connected in shunt and the output is connected in series with the transmission line.

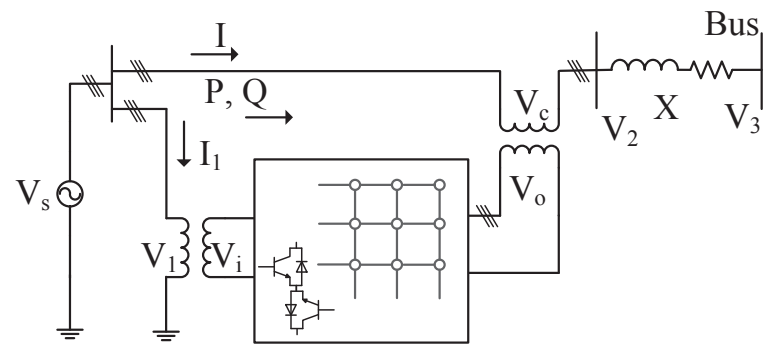

Fig. 5: Proposed Matrix Converter Based UPFC System

\section{Matrix Converter Direct SVM Modulation}

Space Vector Modulation is adopted in this paper to control the output voltage and input current of the matrix converter. SVM is based on PWM theory to synthesize the instantaneous space vector representation of the desired output voltages and input currents. Switch matrix is arranged so that any outputs can be connected to any inputs. The allowed number of switch-state combinations is 27 in total considering the constraints avoiding short circuits at the source side and open circuits at the inductive load side.

The balanced three-phase input phase voltages are

$$
\begin{aligned}
& V_{A}=V_{i} \sin \left(\omega_{i} t\right) \\
& V_{B}=V_{i} \sin \left(\omega_{i} t-\frac{2 \pi}{3}\right) ; V_{C}=V_{i} \sin \left(\omega_{i} t+\frac{2 \pi}{3}\right)
\end{aligned}
$$


where $V_{\mathrm{i}}$ is the input phase voltage amplitude and $\omega_{\mathrm{i}}=2 \pi f_{\mathrm{i}}$ is the input angular frequency. The output current can be obtained from:

$$
\begin{aligned}
& I_{a}=I_{o} \sin \left(\omega_{o} t-\varphi_{o}\right) \\
& I_{b}=I_{o} \sin \left(\omega_{o} t-\varphi_{o}-\frac{2 \pi}{3}\right) ; I_{c}=I_{o} \sin \left(\omega_{o} t-\varphi_{o}+\frac{2 \pi}{3}\right)
\end{aligned}
$$

where $I_{\mathrm{o}}$ is the output current amplitude, $\omega_{\mathrm{o}}=2 \pi f_{\mathrm{o}}$ the output angular frequency and $\varphi_{\mathrm{o}}$ the angle difference between the output voltage and output current.

The 3-phase system can be expressed by space vectors using

$$
x_{S}=\frac{2}{3}\left(x_{1}+a x_{2}+a^{2} x_{3}\right)
$$

where $x_{1}, x_{2}$ and $x_{3}$ are the 3-phase variables in the system; $a=\mathrm{e}^{j(2 \pi / 3)}$ and $a^{2}=\mathrm{e}^{j(4 \pi / 3)}$, and $x_{\mathrm{S}}$ is the corresponding space vector after the transformation. The combinations can be classified into the following three groups.

Group I (Active States): two outputs are connected to the same input while the remaining output is connected to one of the other inputs. These 18 active states have fixed direction but their amplitudes vary with the instantaneous values of input voltages.

Group II (Zero States): all three outputs are connected to the same input. These 3 states have zero amplitude and arbitrary directions.

Group III (Rotating States): all three outputs are connected to different inputs. These 6 rotating vectors rotate with fixed amplitudes.

Among the 27 available states only 21 states (18 in Group and 3 in Group II) are employed to synthesize the desired output voltage vectors and input current vectors [10]. Active input voltage and output current vectors are plotted and they form hexagons as shown in Fig. 6. The desired output voltages are

$$
\begin{aligned}
& V_{a}=V_{o} \sin \left(\omega_{o} t\right) \\
& V_{b}=V_{o} \sin \left(\omega_{o} t-\frac{2 \pi}{3}\right) ; V_{c}=V_{o} \sin \left(\omega_{o} t+\frac{2 \pi}{3}\right)
\end{aligned}
$$

and the input currents are also transformed using (6) to determine the location of the desired vectors at any instant:

$$
\begin{aligned}
& I_{A}=I_{i} \sin \left(\omega_{i} t-\varphi_{i}\right) \\
& I_{B}=I_{i} \sin \left(\omega_{i} t-\varphi_{i}-\frac{2 \pi}{3}\right) ; I_{C}=I_{i} \sin \left(\omega_{i} t-\varphi_{i}+\frac{2 \pi}{3}\right)
\end{aligned}
$$

where $V_{\mathrm{o}}$ and $I_{\mathrm{i}}$ are the amplitude of expected output voltages and input currents, and $\varphi_{\mathrm{i}}$ the input power factor angle.

In space vector modulation the nearest adjacent vectors to the present sector are used to form the required vectors while the application of non-adjacent vectors may produce higher THD and switching losses [11]. The chosen vectors must accomplish the synthesis of both the output voltages and input currents and they are summarized in Table 1. In order to illustrate the algorithm, without loss of generality, it is assumed that, at a given time instant, the desired output voltage and input current vectors both lie in their corresponding sector (1) shown in Fig. 6.

The expected output space vector and input current vector can be resolved into $V_{\alpha}$ and $V_{\beta}$, and $I_{\gamma}$ and $I_{\delta}$, respectively, as shown in Fig. 7. Once the switch states are determined (Table $1)$ the corresponding duty cycles are calculated. According to Figs. 6 and 7, and Table 1, the duty cycles are given by

$$
\begin{aligned}
& t_{x 1}=(-1)^{m+n} \frac{2}{\sqrt{3}} T_{P} q \frac{\sin (\theta) \sin (\rho)}{\cos \left(\varphi_{i}\right)} \\
& t_{x 2}=(-1)^{m+n+1} \frac{2}{\sqrt{3}} T_{P} q \frac{\sin (\theta) \sin (\pi / 3-\rho)}{\cos \left(\varphi_{i}\right)} \\
& t_{y 1}=(-1)^{m+n+1} \frac{2}{\sqrt{3}} T_{P} q \frac{\sin (\pi / 3-\theta) \sin (\rho)}{\cos \left(\varphi_{i}\right)} \\
& t_{y 2}=(-1)^{m+n} \frac{2}{\sqrt{3}} T_{P} q \frac{\sin (\pi / 3-\theta) \sin (\pi / 3-\rho)}{\cos \left(\varphi_{i}\right)} \\
& t_{0}=T_{P}-\left(\left|t_{x 1}\right|+\left|t_{x 2}\right|+\left|t_{y 1}\right|+\left|t_{y 2}\right|\right) \\
& q=\frac{V_{o}}{V_{i}} \leq\left|\frac{\sqrt{3} \cos \left(\varphi_{i}\right)}{2 \sin (\theta+\pi / 3) \sin (\rho+\pi / 3)}\right|
\end{aligned}
$$

where $0 \leq \theta \leq \pi / 3$ is the angle between the desired output space vector $V_{\text {os }}$ and the right-hand adjacent vector $V_{\alpha} ; 0 \leq \rho \leq$ $\pi / 3$ is the angle between the desired input space vector $I_{\text {is }}$ and the right-hand adjacent vector $I_{\gamma} ; t_{\mathrm{x} 1}, t_{\mathrm{x} 2}$ and $t_{\mathrm{y} 1}, t_{\mathrm{y} 2}$ are the working times corresponding to the chosen vectors; $T_{\mathrm{p}}$ is the cycle period; and $m$ and $n$ denote the $m^{\text {th }}$ output voltage vector sector and the $n^{\text {th }}$ input current vector sector $(m, n=1,2,3,4$, 5 , 6). If any of the working times are negative, the corresponding negative vector should be selected instead of the assumed positive vector shown in Table 1 . Note that the correct commutation technique helps improve the power quality and dead time effect.

\section{Power Flow Controller}

\subsection{Model Description}

The case study for simulation is shown in Fig. 8. The mathematical model of the transmission line $X$ is given as

$\frac{d I_{x}}{d t}=\frac{V_{s x}+V_{c x}-V_{r x}}{L}-\frac{R}{L} I_{x}$

where $x=a, b, c$ is the index of the three phases. Using the rotating $\mathrm{d}-\mathrm{q}$ reference frame, the balanced three phase quantities can be represented by $d$ and $q$ components where

$$
\begin{aligned}
& \frac{d I_{d}}{d t}=-\frac{R}{L} I_{d}-\omega I_{q}+\frac{V_{s d}+V_{c d}-V_{r d}}{L} \\
& \frac{d I_{q}}{d t}=-\frac{R}{L} I_{q}+\omega I_{d}+\frac{V_{s q}+V_{c q}-V_{r q}}{L}
\end{aligned}
$$

If the reference frame is synchronized with the source voltage, then the $q$ component of the source voltage is 0 . And the active power and reactive power through the transmission line are expressed by 


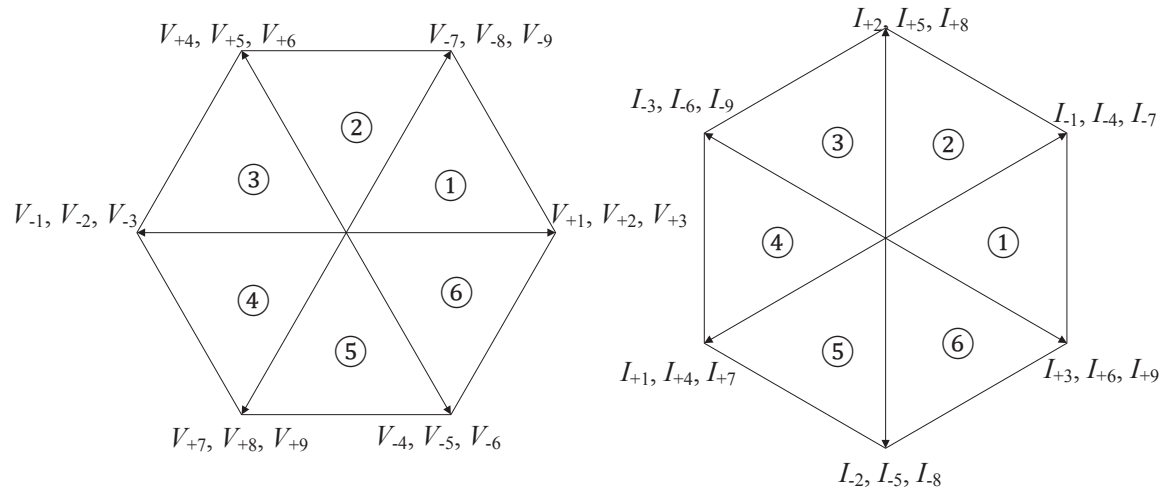

Fig. 6: Space Vectors Hexagon for Output Voltages and Input Currents
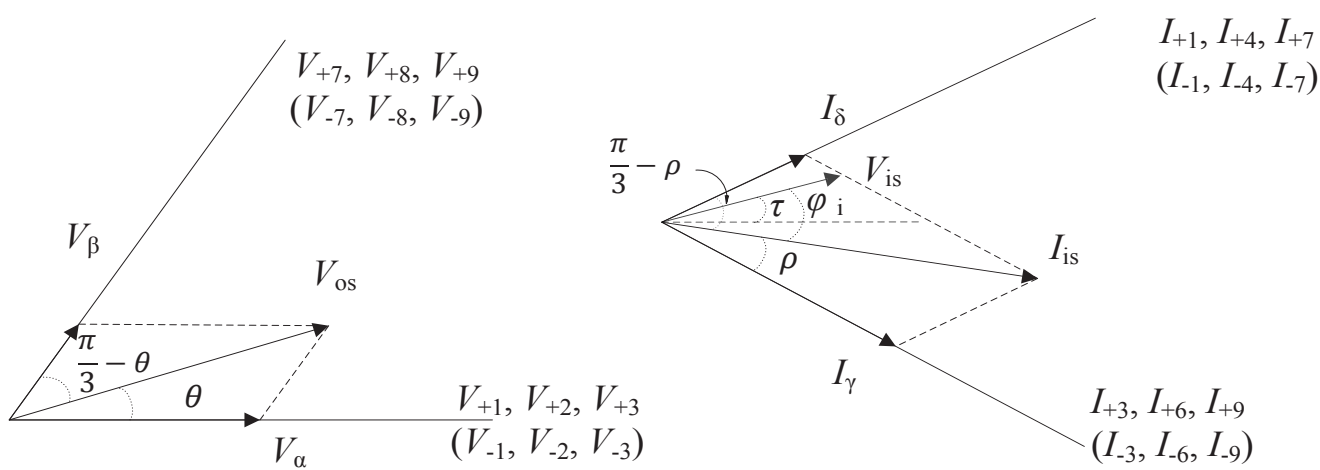

Fig. 7: Synthesis of Desired Output Voltage and Input Current Vector

\begin{tabular}{|c|c|c|c|c|c|c|c|}
\hline \multicolumn{8}{|c|}{ Sector number of output voltage vector } \\
\hline \multirow{7}{*}{$\begin{array}{l}\text { Sector } \\
\text { number } \\
\text { of } \\
\text { input } \\
\text { current } \\
\text { vector }\end{array}$} & & 1 & 2 & 3 & 4 & 5 & 6 \\
\hline & 1 & $+7,+9,+1,+3$ & $+4,+6,+7,+9$ & $+1,+3,+4,+6$ & $+7,+9,+1,+3$ & $+4,+6,+7,+9$ & $+1,+3,+4,+6$ \\
\hline & 2 & $+8,+7,+2,+1$ & $+5,+4,+8,+7$ & $+2,+1,+5,+4$ & $+8,+7,+2,+1$ & $+5,+4,+8,+7$ & $+2,+1,+5,+4$ \\
\hline & 3 & $+9,+8,+3,+2$ & $+6,+5,+9,+8$ & $+3,+2,+6,+5$ & $+9,+8,+3,+2$ & $+6,+5,+9,+8$ & $+3,+2,+6,+5$ \\
\hline & 4 & $+7,+9,+1,+3$ & $+4,+6,+7,+9$ & $+1,+3,+4,+6$ & $+7,+9,+1,+3$ & $+4,+6,+7,+9$ & $+1,+3,+4,+6$ \\
\hline & 5 & $+8,+7,+2,+1$ & $+5,+4,+8,+7$ & $+2,+1,+5,+4$ & $+8,+7,+2,+1$ & $+5,+4,+8,+7$ & $+2,+1,+5,+4$ \\
\hline & 6 & $+9,+8,+3,+2$ & $+6,+5,+9,+8$ & $+3,+2,+6,+5$ & $+9,+8,+3,+2$ & $+6,+5,+9,+8$ & $+3,+2,+6,+5$ \\
\hline & & \begin{tabular}{l|l|l|l}
$\mathrm{t}_{\mathrm{x} 1}$ & $\mathrm{t}_{\mathrm{x} 2}$ & $\mathrm{t}_{\mathrm{y} 1}$ & $\mathrm{t}_{\mathrm{y} 2}$
\end{tabular} & \begin{tabular}{|l|l|l|l|}
$\mathrm{t}_{\mathrm{x} 1}$ & $\mathrm{t}_{\mathrm{x} 2}$ & $\mathrm{t}_{\mathrm{y} 1}$ & $\mathrm{t}_{\mathrm{y} 2}$
\end{tabular} & \begin{tabular}{l|l|l|l|l}
$\mathrm{t}_{\mathrm{x} 1}$ & $\mathrm{t}_{\mathrm{x} 2}$ & $\mathrm{t}_{\mathrm{y} 1}$ & $\mathrm{t}_{\mathrm{y}}$
\end{tabular} & & & \\
\hline
\end{tabular}

Table 1: Vector Combinations to Synthesize the Desired Voltages and Currents

$$
\begin{aligned}
& P=\frac{3}{2} V_{s d} I_{d} \\
& Q=-\frac{3}{2} V_{s d} I_{q}
\end{aligned}
$$

Consequently, the reference $d$ and $q$ components of the current correspond to the $\mathrm{P}$ and $\mathrm{Q}$ references so that

$$
\begin{aligned}
& I_{d}=\frac{2}{3} \frac{P}{V_{s d}} \\
& I_{q}=-\frac{2}{3} \frac{Q}{V_{s d}}
\end{aligned}
$$

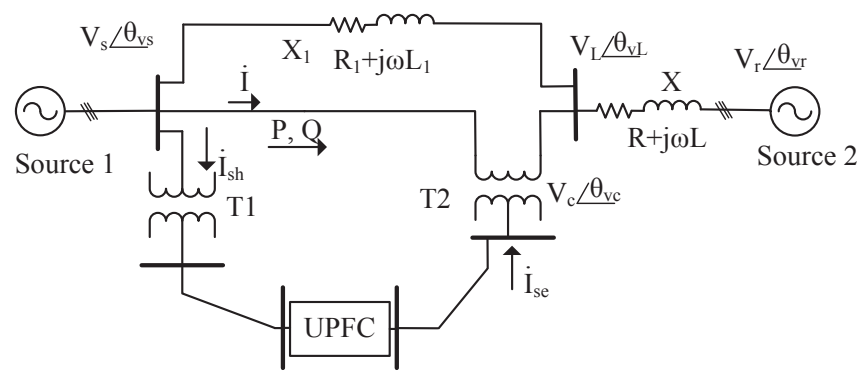

Fig. 8: UPFC System of Simulation Study Case 


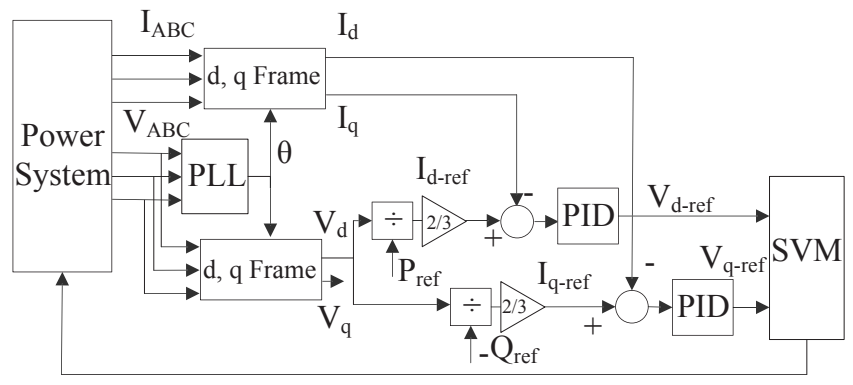

Fig. 9: PID Power Flow Controller

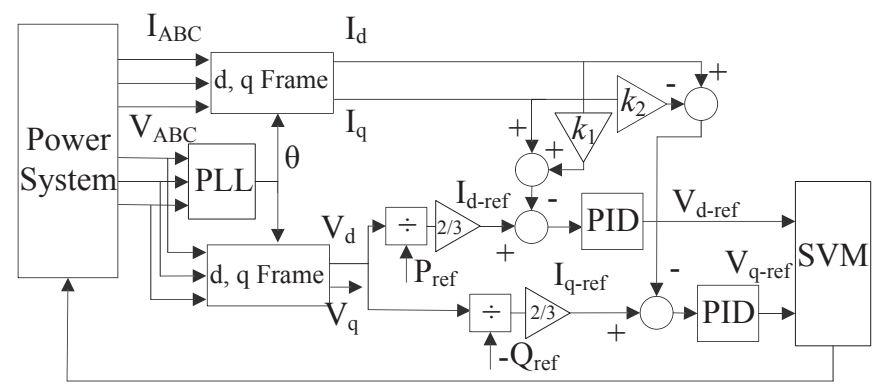

Fig. 10: d-q Coupling Suppressed PID Controller

\subsection{Controller Design}

On the basis of the above description the PID controllers are designed and shown in Fig. 9. A Phase Locked Loop (PLL) is used to detect the ramp for the frame transformation.

In order to reduce the $\mathrm{d}-\mathrm{q}$ coupling effects, the $\mathrm{d}-\mathrm{q}$ components are fed into the each PID controller. As a result, the d-q-coupling-suppressed PID controller is obtained as shown in Fig. 10.

\section{Simulation and Results}

The simulation is implemented for the case shown in Fig. 8. The system parameters and controller parameters are given in Tables 2 and 3respectively. In the section, only the simulation results for d-q coupling suppressed PID controller are given because of its good performance and negligible steady state errors.

\begin{tabular}{|c|c|c|c|}
\hline$V_{\mathrm{s}}(\mathrm{V})$ & $V_{\mathrm{r}}(\mathrm{V})$ & $X(\Omega)$ & $X_{1}(\Omega)$ \\
\hline 220 & $212.503-j 56.94$ & $10.667+j 50.265$ & $2+j 18.85$ \\
\hline
\end{tabular}

Table 2: System Parameters of Simulation

\begin{tabular}{|c|c|c|c|c|c|c|c|}
\hline Kp1 & Ki1 & Kd1 & Kp2 & Ki2 & Kd2 & K1 & K2 \\
\hline 3 & 0.03 & 0 & 11 & 0.06 & 0.05 & 0.09 & 0.001 \\
\hline
\end{tabular}

Table 3: Parameters of the Controller
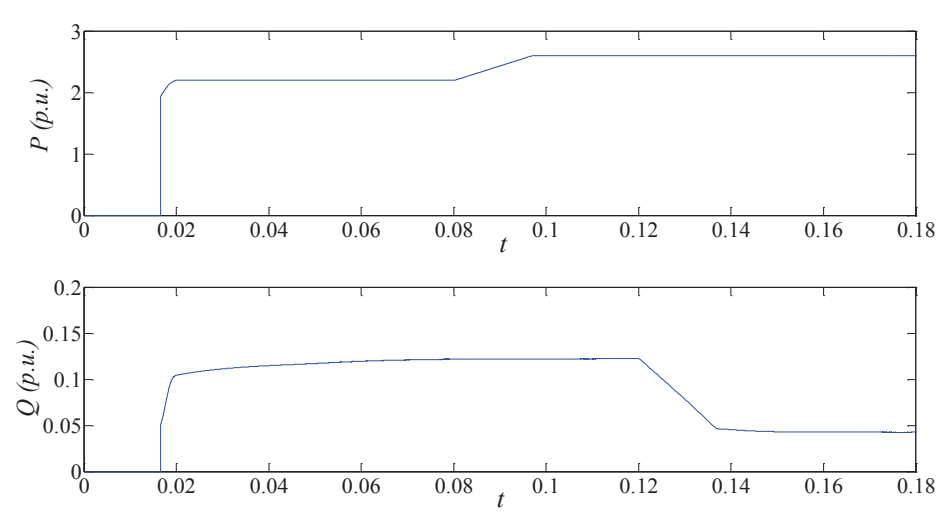

Fig. 11: Compensated Bus Active and Reactive Powers (p.u.)
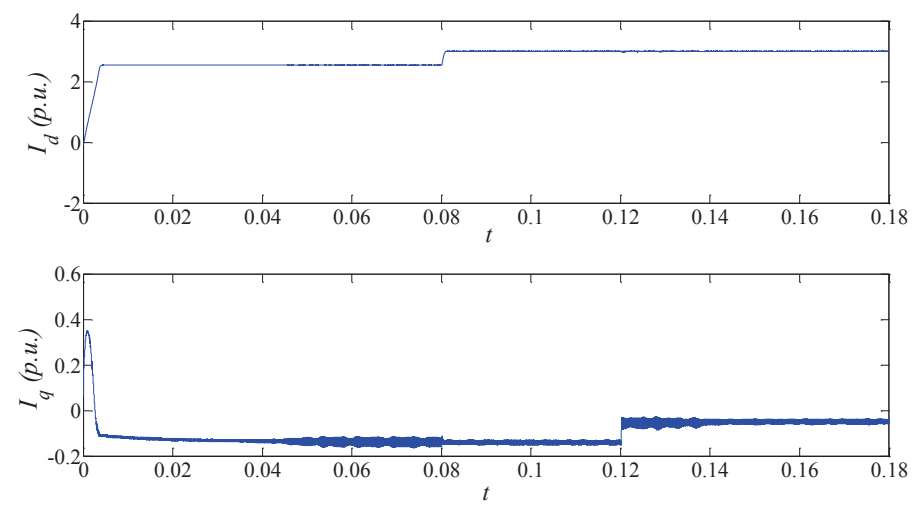

Fig. 12: d-q Components of the Bus Current (p.u.)
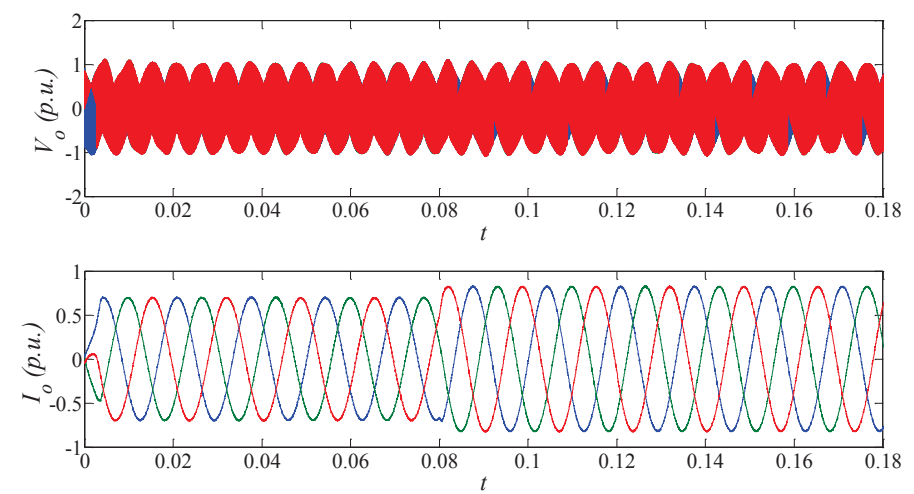

Fig. 13: Matrix Converter Three-Phase Output Voltages and Currents (p.u.)
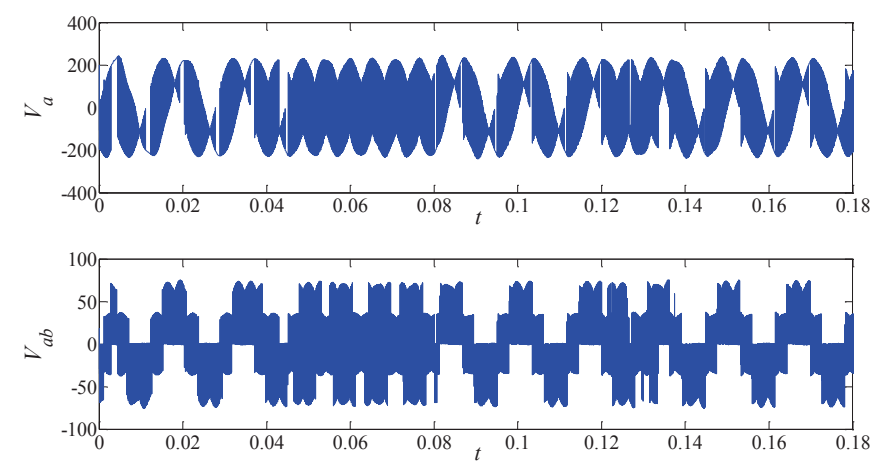

Fig. 14: Injected Phase Voltage and Line Voltage of Phase a 

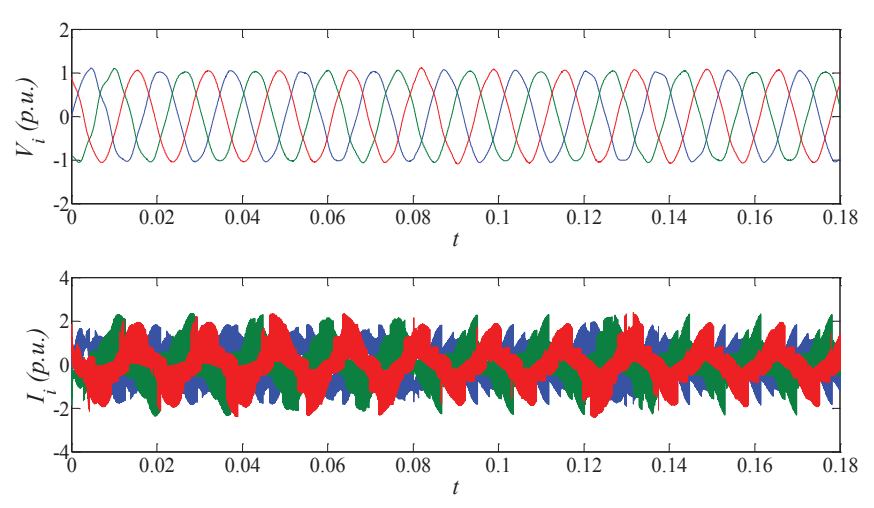

Fig. 15: Matrix Converter Three-Phase Input Voltages and Currents (p.u.)
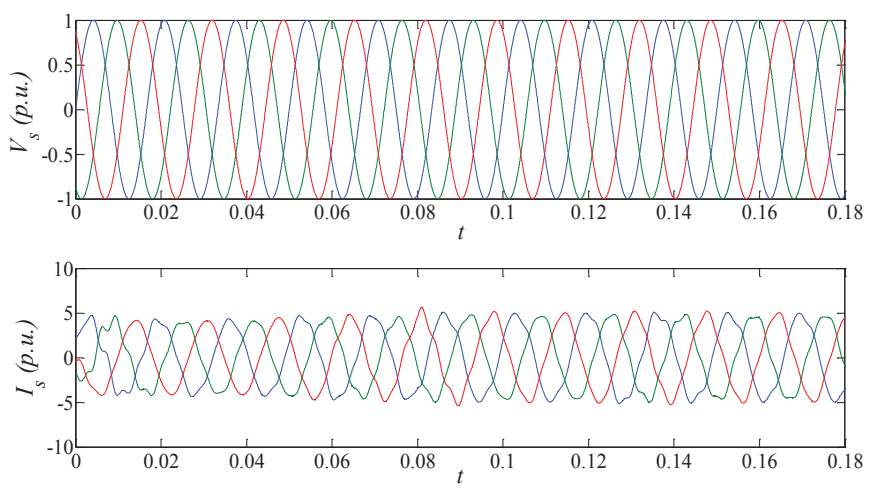

Fig. 16: Supply Source Voltages and Currents (p.u.)

The RLC ( $R=1 \Omega, L=10 \mathrm{mH}$ and $C=10 \mu \mathrm{F})$ filters are used at the input terminals of the matrix converter to improve the power quality to the grid. Simulation results are shown in Figs. 11 to 16 . Fig. 11 shows the active and reactive power flowing though the bus line. The active power reference is set as 2.2 p.u. before $0.08 \mathrm{~s}$ and 2.6 p.u. after $0.08 \mathrm{~s}$, while the reactive power reference is set as 0.12 p.u. before $0.12 \mathrm{~s}$ and 0.04 p.u. after $0.12 \mathrm{~s}$. As shown, the output can be controlled to track the references effectively, and the d-q coupling effect is suppressed. The d-q components of the compensated bus current change according to the power demand as shown in Figs. 12 and 13. Figs. 14 and 15 show the voltages and currents of the matrix converter. The voltages and currents of the supply source are shown in Fig. 16. It can be seen that the proposed strategy can effectively improve the transmission capacity of the transmission system and compensate the reactive power.

\section{Conclusions}

The bulky storage elements in a traditional UPFC increase the volume and weight, reduce the lifetime of the device and decrease the efficiency. A matrix converter is proposed as a potential alternative to the back-to-back converter used in the AC-to-AC conversion. PID controllers are combined with the space vector modulation, and these are employed to produce the desired output voltages which are injected into the transmission line to compensate the active and reactive powers. Furthermore, the $\mathrm{d}$ and $\mathrm{q}$ components are fed to the controller to reduce the d-q coupling effects. The proposed controller can track the references effectively and it has good dynamics. The steady state errors are negligible. The simulation results validate the effectiveness of the proposed scheme. Experimental implementation is expected in future work.

\section{Acknowledgements}

This work is supported in part by the China Scholarship Council (File No. 201406300161).

\section{References}

[1] R. Strzelecki, A. Noculak, H. Tunia, K. Sozanski and Z. Fedyczak, "UPFC with matrix converter," EPE conf., Graz, Austria, Sep. 2001.

[2] L. Gyugyi, "Unified power-flow control concept for flexible AC transmission systems," IEE proceedings $C$ (generation, transmission and distribution), vol. 139, no. 4, pp. 323-331, 1992.

[3] N. G. Hingorani and L. Gyugyi, "Understanding FACTS: concepts and technology of flexible AC transmission systems," Wiley-IEEE press, 2000.

[4] P. Q. Dzung, "A new artificial neural network-Direct torque control for matrix converter fed three-phase induction motor," Int. Conf. on Power Electron. and Drives Syst., vol. 1, pp. 78-83, 2005.

[5] J. Monteiro, J. F. Silva, S. F. Pinto, and J. Palma, "Matrix converter-based unified power-flow controllers: Advanced direct power control method," Power Delivery, IEEE Trans. Power Del., vol. 26, no. 1, pp. 420-430, 2011.

[6] P. W. Wheeler, J. Rodriguez, J. C. Clare, L. Empringham and A. Weinstein, "Matrix converters: a technology review," IEEE Trans. Ind. Electron., vol. 49, no. 2, pp. 276-288, 2002.

[7] L. Huber and D. Borojevic, "Space vector modulator for forced commutated cycloconverters," Ind. Applicat. Soc. Annu. Meeting Conf. Rec., pp. 871-876, 1989.

[8] J. F. Verveckken, A. Silva, and J. Driesen, "Design of inverse controller with cross-coupling suppression for UPFC series converter," The Int. Conf. on Comput. as a Tool, pp. 2613-2619, 2007.

[9] S. D. Round, Q. Yu, L. E. Norum, and T. M. Undeland, "Performance of a unified power flow controller using a dq control system," 6th Int. Conf. on AC and DC Power Transmission, pp. 357-362 (1996).

[10] J. W. Kolar, T. Friedli, J. Rodriguez, and P. W. Wheeler, "Review of three-phase PWM AC-AC converter topologies," IEEE Trans. Ind. Electron., vol. 58, no. 11, pp. 4988-5006, 2011.

[11] V. H. Prasad, "Analysis and Comparison of Space Vector Modulation schemes for Three-Leg and FourLeg Voltage Source inverters, " Master Thesis, Virginia Polytechnic Institute and State University, US, May 1997. 